\title{
Malaria in pregnant women living in areas of low transmission on the southeast Brazilian Coast: molecular diagnosis and humoural immunity profile
}

\author{
Angélica Domingues Hristov $1 /{ }^{+}$, Maria Carmen Arroyo Sanchez ${ }^{2}$, José Jarbas Bittencourt Ferreira ${ }^{3}$, \\ Giselle Fernandes Maciel de Castro Lima', Juliana Inoue ${ }^{1}$, Maria de Jesus Costa-Nascimento ${ }^{4}$, \\ Arianni Rondelli Sanchez ${ }^{2}$, Eduardo Milton Ramos-Sanchez ${ }^{2}$, Silvia Maria Di Santi ${ }^{1,4}$ \\ 1Departamento de Moléstias Infecciosas e Parasitárias, Faculdade de Medicina ²Laboratório de Soroepidemiologia e Imunobiologia \\ ${ }^{4}$ Núcleo de Estudos em Malária, Superintendência de Controle de Endemias, Instituto de Medicina Tropical de São Paulo, \\ Universidade de São Paulo, São Paulo, SP, Brasil ${ }^{3}$ Prefeitura Municipal de Juquitiba, SP, Brasil
}

Studies on autochthonous malaria in low-transmission areas in Brazil have acquired epidemiological relevance because they suggest continued transmission in what remains of the Atlantic Forest. In the southeastern portion of the state of São Paulo, outbreaks in the municipality of Juquitiba have been the focus of studies on the prevalence of Plasmodium, including asymptomatic cases. Data on the occurrence of the disease or the presence of antiplasmodial antibodies in pregnant women from this region have not previously been described. Although Plasmodium falciparum in pregnant women has been widely addressed in the literature, the interaction of Plasmodium vivax and Plasmodium malariae with this cohort has been poorly explored to date. We monitored the circulation of Plasmodium in pregnant women in health facilities located in Juquitiba using thick blood film and molecular protocols, as well as immunological assays, to evaluate humoural immune parameters. Through real-time and nested polymerase chain reaction, P. vivax and $\mathrm{P}$. malariae were detected for the first time in pregnant women, with a positivity of $5.6 \%$. Immunoassays revealed the presence of IgG antibodies: $44 \%$ for ELISA-Pv, 38.4\% for SD-Bioline-Pv and 18.4\% for indirect immunofluorescence assay-Pm. The high prevalence of antibodies showed significant exposure of this population to Plasmodium. In regions with similar profiles, testing for a malaria diagnosis might be indicated in prenatal care.

Key words: autochthonous malaria - pregnancy - molecular diagnostic techniques - humoural - immunity - asymptomatic infections

Pregnant women and children are the main groups at risk of acquiring malaria worldwide. Every year, 125 million women from endemic countries become pregnant. In areas of low transmission for Plasmodium falciparum, pregnant women have little or no immunity against the disease and usually suffer severe episodes of malaria. In areas of high or moderate transmission, there are significant levels of acquired immunity and the effects on the mother and foetus are less severe. Although malaria caused by $P$. falciparum in pregnant women has been widely investigated, the interaction of this cohort with Plasmodium vivax and Plasmodium malariae requires a more comprehensive approach. The World Health Organization (WHO) recommends four antenatal care visits, including malaria tests. However, this criterion depends on the local conditions and specific orientations for each area (Dellicour et al. 2010, WHO 2013). P. vivax is responsible for most cases of malaria in Asia and the Americas, with reports of morbidity in pregnant women and

doi: 10.1590/0074-0276140229

Financial support: SUCEN, PROAP/CAPES, CNPq, PRPG/USP

+ Corresponding author: angelicadh@usp.br

Received 25 June 2014

Accepted 8 December 2014 serious consequences, such as maternal anaemia and low birth weight in children (Nosten et al. 1999). The geographic distribution of $P$. malariae infections in pregnant women and the adverse effects on maternal and newborn health are unknown (Dellicour et al. 2010).

In Brazil, $99 \%$ of malaria infections occur in the Amazon Region and 166,864 cases were registered in 2013 (MS 2014a). Martínez-Espinosa (2003) reported a prevalence of $4.3 \%$ in pregnant women in the municipality of Coari, state of Amazonas. Non-pregnant women of the same age showed a positivity of $0.8 \%$. Luz et al. (2013) reported that in 2007, malaria cases diagnosed in pregnant women comprised $6.7 \%$ of fertile-age women in three municipalities located in the Amazon Region. $P$. vivax was the most predominant species $(80 \%)$. From the 13,308 malaria cases reported in Manaus from 2003-2006 among women aged $10-49$ years, $6.1 \%$ were in pregnant women. P. vivax was responsible for $85 \%$ of the infections and P. falciparum for $14.3 \%$ (Almeida et al. 2010).

Although malaria is not considered endemic outside the Brazilian Amazon Region, autochthonous cases are registered in areas covered by the Atlantic Forest. This biome, distributed in 17 coastal states, comprises a unique ecosystem in which important mountain ranges are located. In this region, from 2012-2013, 188 autochthonous cases were reported. The states of Espírito Santo (ES), São Paulo (SP) and Piauí (PI) reported 72.3\% of the infections, with 75, 43 and 27 cases, respectively (MS 2014b). In a retrospective study conducted in SP 
from 1980-2007, P. vivax accounted for $97.2 \%$ of 816 malaria autochthonous cases, most of which were transmitted along the Atlantic Coast. The main symptoms were fever, headache and chills and $9.6 \%$ were asymptomatic (Couto et al. 2010). In the southeastern part of SP, malaria outbreaks have been reported in the municipality of Juquitiba, located in the Atlantic Forest biome, where surveys on Plasmodium's occurrence show the presence of submicroscopic parasitaemias and asymptomatic cases in inhabitants (Branquinho et al. 1997). In this region, where the transmission of $P$. vivax was established by several studies (Carvalho et al. 1988), our group detected, for the first time using molecular tools, the occurrence of $P$. malariae (Kirchgatter et al. 2005). In addition, the transmission in this region seems to involve wild primates that act as reservoirs for Plasmodium brasilianum and Plasmodium simium (Curado et al. 2006). The primary vectors involved in this scenario are Anopheles (Kerteszia) cruzii and Anopheles (K.) bellator; however, Anopheles (N.) marajoara may participate in the dynamics of malaria transmission. Anopheles (K.) cruzii is present mainly in the forested slopes of the Serra do Mar, $A n$. (K.) bellator in the coastal land and An. (N.) marajoara in the deforested areas (Laporta et al. 2011).

Despite autochthonous malaria transmission reports having been well established outside the Amazon Region, there is a lack of data on the prevalence of autochthonous malaria in pregnant women living in lowendemicity areas of Brazil. In this study, we aimed to determine the frequency of pregnant women harbouring Plasmodium and the level of antiplasmodial antibodies in a cohort living in a low-endemicity area.

\section{SUBJECTS, MATERIALS AND METHODS}

Study area and population - Juquitiba is located 71 $\mathrm{km}$ from the capital of SP (Fig. 1) in the Atlantic Forest biome, at an altitude of $685 \mathrm{~m}$. Approximately $67 \%$ of its length is covered by bushland and the preserved native forest promotes great movement of individuals due to ecotourism. Juquitiba has a population of 28,737 inhabitants, of whom $49.42 \%$ are female (Brazilian Institute

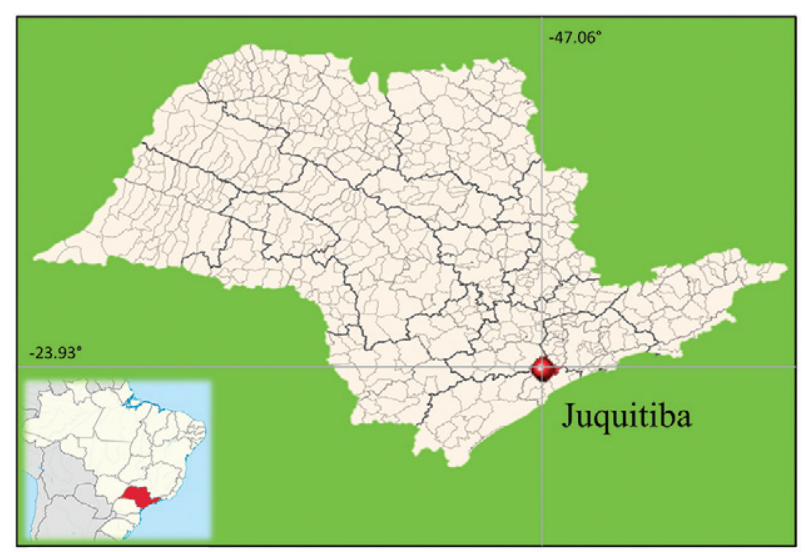

Fig. 1: location of the municipality of Juquitiba. The small map on the left shows the location of the state of São Paulo, Brazil. of Geography and Statistics, available from: ibge.gov. br/home/estatistica/populacao/censo2010/tabelas_pdf/ total_populacao_sao_paulo.pdf). Approximately 450 pregnant women are recorded annually, according to the health secretary of the municipality. These women receive prenatal care in five public healthcare units: Centro, Barnabés, Justino, Jardim das Palmeiras and Palmeiras.

Study design and data collection - This is a prospective cohort study with no probabilistic consecutive sampling. The population at risk was defined as childbearing age women (10-49 years) living in Juquitiba, a definition that encompassed 9,169 women (Brazilian Institute of Geography and Statistics, available from: ibge.gov.br/ home/estatistica/populacao/censo2010/tabelas_pdf/total_populacao_sao_paulo.pdf). The inclusion criterion was pregnant women of any age living in Juquitiba and the exclusion criterion was the presence of any infectious disease other than malaria. The exposure variable was defined to encompass pregnant women living in or having been displaced to areas near the forest in Juquitiba. The outcome variable was the presence of parasites in the cohort of pregnant women. The pregnant women were invited to participate in the study at the time they received prenatal care in the five health facilities in the municipality. Blood collections were held in the five healthcare units of the municipality, between October 2012-November 2013, by signing the informed consent form. At the moment of inclusion, each pregnant woman answered a questionnaire with the assistance of a health professional with regard to her address, age, civil status, race, a previous pregnancy history, any personal and/or family history of malaria, any displacement to endemic areas, a clinical description, the presence of infectious disease and other health issues.

Collection and samples processing - Peripheral venous blood was collected in a $5-\mathrm{mL}$ ethylenediamine tetraacetic acid (EDTA) tube in the first, second and third trimesters of pregnancy, according to the time of inclusion in the study. The blood was used to perform a thick blood smear (TBS), polymerase chain reaction (PCR), haemoglobin measurement using $\mathrm{HemoCue}^{\circledR}$ and immunoassays. After centrifugation, the pellets containing the erythrocytes and the plasma were stored at $-20^{\circ} \mathrm{C}$. Blood samples from newborns whose mothers tested positive for malaria were collected by heel punctures. The samples were used to perform TBSs and were plotted on Whatman $3^{\circledR}$ filter paper (Sigma-Aldrich ${ }^{\circledR}$, USA) for DNA extraction and real-time PCR.

Haemoscopy by TBS - All slides were air dried and stained following the Giemsa standard protocol immediately after arriving in the laboratory. Two slides were analysed for each individual. The reading was performed using an immersion lens $(1,000 \mathrm{X})$ until the count of 500 white blood cells (WBC) was reached, which corresponded to $25 \mathrm{~min}$ of observation (WHO 2009). Two investigators without knowledge of the molecular and serological results examined the slides independently.

Genomic DNA extraction - The pellet containing erythrocytes was lysed with $1 \%$ saponin (Sigma-Aldrich) 
and washed and $200 \mu \mathrm{L}$ were used for DNA extraction with a QIAamp ${ }^{\circledR}$ DNA Blood Mini Kit (Qiagen Hilden, Germany). Samples plotted on Whatman $3^{\circledR}$ filter paper (Sigma-Aldrich) were extracted with Chelex $100^{\circledR}$ (Bio$\mathrm{Rad}^{\mathrm{TM}}$, USA) according to a protocol described elsewhere (Plowe et al. 1995).

Real-time PCR - The protocol described by Lima et al. (2011) was applied for genus-specific amplification targeting the ssrRNA gene of Plasmodium. The M60 and M61 primers and the M62 probe were used and the reactions were performed with $2.5 \mu \mathrm{L}$ of gDNA, 12.5 $\mu \mathrm{L}$ of $2 \mathrm{x}$ TaqMan ${ }^{\circledR}$ Universal PCR Master Mix, $500 \mathrm{nM}$ of each primer and $300 \mathrm{nM}$ of FAM ${ }^{\mathrm{TM}}$ and TAMRA $\mathrm{TM}_{-}$ labelled probe (Applied Biosystems, USA). Amplification and detection were carried out according the following procedure: $50^{\circ} \mathrm{C}$ for $2 \mathrm{~min}$ and $95^{\circ} \mathrm{C}$ for $15 \mathrm{~min}$, followed by 40 cycles at $94^{\circ} \mathrm{C}$ for $30 \mathrm{~s}$ and a final cycle at $60^{\circ} \mathrm{C}$ for $1 \mathrm{~min}$. Duplicate samples were assayed on the ABI Prism 7300 system (Applied Biosystems) using negative (ultrapure water) and positive controls (Plasmodium DNA from a 1 parasite/ $\mu \mathrm{L}$ culture). To monitor the performance of real-time PCR, DNA from P. falciparum in vitro cultures was included in all assays to obtain a standard curve, with parasitaemias ranging from 350 0.35 parasites $/ \mu \mathrm{L}$. A cut-off was established based on the average plus 2 standard deviations (SD) of the threshold cycle $(\mathrm{Ct})$ values from the $P$. falciparum samples with 1 parasite $/ \mu \mathrm{L}$, included in all plates.

Nested PCR - The samples with positive results in the real-time PCR were processed by nested PCR using ssrRNA genes as the targets (Snounou et al. 1993). The first reaction employed the genus-specific primers rPLU5 and rPLU6 and the second reaction used speciesspecific primers for $P$. falciparum, $P$. malariae and $P$. vivax. The reaction was prepared with $25 \mu \mathrm{L}$, consisting of $250 \mathrm{nM}$ of each primer, $125 \mu \mathrm{M}$ of deoxynucleoside triphosphates, $2 \mathrm{mM} \mathrm{MgCl}, 50 \mathrm{mM} \mathrm{KCl}, 10 \mathrm{mM}$ Tris $\mathrm{pH} 8.3,0.4 \mathrm{U}$ Taq polymerase and $2 \mu \mathrm{L}$ of genomic DNA. The cycling conditions were as follows: $95^{\circ} \mathrm{C}$ for $5 \mathrm{~min}$, $58^{\circ} \mathrm{C}$ for $2 \mathrm{~min}$ and $72^{\circ} \mathrm{C}$ for $2 \mathrm{~min}$, followed by 24 cycles at $94^{\circ} \mathrm{C}$ for $1 \mathrm{~min}, 58^{\circ} \mathrm{C}$ for $2 \mathrm{~min}$ and $72^{\circ} \mathrm{C}$ for $2 \mathrm{~min}$ and ending with $72^{\circ} \mathrm{C}$ for $5 \mathrm{~min}$. In the second reaction, 30 cycles of amplification were performed under the same conditions, adding $1 \mu \mathrm{L}$ of the first reaction product. The fragments were separated by electrophoresis in $1.5 \%$ agarose/tris-borate-EDTA gel and visualised with ethidium bromide through ultraviolet light. Negative (ultrapure water) and positive controls (gDNA of $P$. falciparum, $P$. vivax and $P$. malariae) were included in all tests.

ELISA - An adapted protocol described elsewhere was applied for the detection of $\mathrm{IgG}$ antibodies against $P$. falciparum and $P$. vivax. Crude $P$. falciparum antigen was extracted with Zwittergent ${ }^{\circledR}$ (Calbiochem $^{\circledR}$, Germany) and employed at $0.5 \mu \mathrm{g} / \mathrm{mL}$ for the detection of IgG antibodies against all Plasmodium species through cross-reactions (Sanchez et al. 1993, Coelho et al. 2007). To detect $P$. vivax antibodies, the recombinant antigen $\mathrm{His}_{6} P v \mathrm{MSP}_{19}$ was used at $4 \mu \mathrm{g} / \mathrm{mL}$ (Coelho et al. 2007). The plasmid pET14b-PvMSP1 ${ }_{19}$ (kindly provided by Dr Irene Silva Soares) was expressed in Escherichia coli BL21-CodonPlus ${ }^{\circledR}$ (DE3)-RIL (Stratagene, USA) and purified by affinity chromatography using the ProBond $^{\mathrm{TM}}$ Purification System (Life Technologies, USA) under denaturing conditions, according to the manufacturer's instructions. Plates were coated with the antigen for $2 \mathrm{~h}$ at $37^{\circ} \mathrm{C}$ and overnight at $4^{\circ} \mathrm{C}$ and blocking was performed with $5 \%$ skim milk at $37^{\circ} \mathrm{C}$ for $2 \mathrm{~h}$. The plasma samples were diluted to $1 / 100$ for the assays. Anti-human IgG (Fc specific)-peroxidase antibody produced in goats (Sigma-Aldrich) was used at a dilution of 1: 20.000. The enzymatic reaction was conducted using tetramethylbenzidin $/ \mathrm{H}_{2} \mathrm{O}_{2}$ (Life Technologies) at room temperature in dark conditions. The reaction was interrupted with $2 \mathrm{~N} \mathrm{H}_{2} \mathrm{SO}_{4}$ (Merck, Germany). A spectrophotometric reading at $450 \mathrm{~nm}$ was performed on a Titertek Multiskan MCC/340 (Labsystems Diagnostics Group, Finland). The cut-off of each reaction was determined using the receiver operating characteristic (ROC) curve from the absorbances of the positive and negative samples (Greiner et al. 2000). The reactivity index (RI) $(\mathrm{RI}=$ absorbance/cut-off $)$ was calculated and samples with $\mathrm{RI} \geq 1$ were considered positive.

Indirect immunofluorescence assay (IFA) - The protocol by Ferreira and Sanchez (1988) was applied to detect IgG antibodies against $P$. malariae. Multi-spot slides (Thermo Fisher Scientific, USA) were coated with blood collected from a patient infected with $P$. malariae for the first time. Plasma samples diluted to $1 / 40$ were incubated for $30 \mathrm{~min}$ at $37^{\circ} \mathrm{C}$ in a moist chamber and washed three times with phosphate buffered saline for $10 \mathrm{~min}$. Subsequently, the antibody-antigen complex was overlaid with fluorescein isothiocyanate-conjugated goat anti-human $\operatorname{IgG}(\gamma$ chain-specific) at 1/200 (Fluoline G; BioMérieux, France) and incubated according to the same conditions. The slides were mounted in alkaline glycerin and observed under a fluorescence microscope. Positive and negative controls were used for each slide.

SD Bioline Malaria Pf/Pv immunochromatographic test - An immunochromatographic test for the detection of antibodies against $P$. falciparum and $P$. vivax was used according to the manufacturer's instructions. Briefly, $10 \mu \mathrm{L}$ of plasma were dispensed in the device well, followed by $110 \mu \mathrm{L}$ of the assay diluent and the test was interpreted after $15 \mathrm{~min}$. The SD Bioline Malaria $P f /$ $P v$ test detects antibodies against circumsporozoite surface protein (CSP) and merozoite surface protein (MSP) recombinant antigens. The control colour band indicated that the test worked properly.

Statistical analysis - The results were analysed using Microsoft Excel 2013, Sigma Stat 3.5, GraphPad Prism 5.0 and GraphPad Software. The levels of significance were set to accept a type- 1 error of $5 \%(\alpha=0.05)$. The sensitivity and specificity of the ELISA tests and the $95 \%$ confidence intervals $(\mathrm{CI})$ were calculated using the ROC curve. The proportions were compared using Fisher's exact test. The Mann-Whitney $U$ rank sum test was used to compare ranks. The techniques were compared using McNemar's test. The agreement between the results of the techniques was assessed using the Cohen kappa (K) index and its 95\% CI. 
Ethics - This study was approved by the Ethical Committee of the Faculty of Medicine, University of São Paulo, and by the National Committee for Ethics on Research.

\section{RESULTS}

Sampling - Blood samples from 125 pregnant women were collected from October 2012-November 2013 in five healthcare units: Centro (11/125), Barnabés (75/125), Justino (31/125), Palmeiras (2/125) and Jardim das Palmeiras (6/125). The mean age was $24.2( \pm 6.02$; range, 13-40). None of the pregnant women referenced a previous history of malaria or displacement to an endemic area. The number of subjects admitted to the study represented $27.78 \%$ of the 450 pregnant women, which was equal to the average registered in the municipality per year. At the followup, 78 pregnant women underwent second blood collections and 18 underwent second and third collections. Five newborns were tested using TBS and real-time PCR.

Haemoscopy by TBS - Among the 125 samples from the first collection, two tested positive by microscopy, showing positivity $(95 \% \mathrm{CI})$ of $1.6 \%(0.4-5.7)$ after two independent diagnoses. One pregnant woman was positive for $P$. vivax and one for P. malariae. Parasitaemias of the TBSs were calculated as numbers of parasites $/ \mu \mathrm{L}$ :

$\mathrm{P}=\frac{\mathrm{WBC} \text { count } / \mu \mathrm{L} \mathrm{x} \text { number of parasites in } 500 \mathrm{WBC}}{500}$

Both pregnant women showed parasitaemias of 24 parasites $/ \mu \mathrm{L}$ and no newborn of the positive mothers showed Plasmodium infection when tested by TBS.

Real-time PCR and nested PCR - Samples with Cts under 37.28 were considered to be positive in real-time PCR. This value was based on the average of the 1 parasites $/ \mu \mathrm{L}$ controls $\pm 2 \mathrm{SD}$. Of the 125 pregnant women admitted into the study, the samples of seven were amplified by real-time and nested PCR in at least one blood collection (Table I). Among them, six were followed in the Barnabés healthcare unit and one in the Centro healthcare unit. The positivity $(95 \% \mathrm{CI})$ in both PCR assays was $5.6 \%$ (1.7-9.0). P. vivax was detected in three pregnant women and $P$. malariae in four. Positive pregnant women were treated according to Brazilian guidelines: chloroquine at $25 \mathrm{mg} / \mathrm{kg}$ total doses over three days (MS 2010). None of the newborns from positive mothers showed Plasmodium infection when tested using real-time PCR.

Immunoassays - Immunoassays with plasma from all pregnant women included in the study $(\mathrm{n}=125)$ showed positivities $(95 \% \mathrm{CI})$ of $44 \%$ (35.6-52.7) for ELISA- $P v$, 6.4\% (3.3-12.1) for ELISA- $P f$, 38.4\% (30.3-47.1) for SD Bioline $P v, 2.4 \%$ (0.8-6.8) for SD Bioline $P f$ and $18.4 \%$ (12.6-26.1) for IFA-Pm.

The IFA-Pm was considered positive based on the independent readings of two investigators using positive and negative controls. The SD Bioline $P f / P v$ devices were read according to the manufacturer's instructions. Cut-offs for ELISA assays were calculated using ROC curves with positive and negative controls, generating a value of 0.090 for $P$. vivax and 0.200 for $P$. falciparum.

Table II shows the immunoassays' positivities during the quarterly follow-up. Considering all samples collected from the pregnant women $(\mathrm{n}=220)$, positivities $(95 \% \mathrm{CI})$ of 34.6\% (28.3-41.2) for SD Bioline $P v$ and 38.2\% (31.744.9) for ELISA- $P v$ were obtained (McNemar's test, $\mathrm{p}<$ 0.099 ). The strength of agreement between the two assays detecting anti- $P$. vivax $\operatorname{IgG}$ antibodies was considered to be "very good", $\mathrm{k}=0.823$ (95\% CI: 0.746-0.901).

The positivities of the immunoassays varied across the different neighbourhoods. Fig. 2 presents the RI of ELISA- $P v$, showing higher IgG antibodies levels in pregnant women living in Barnabés, Juquitiba. In the first and second collections, comparing Barnabés with all other neighbourhoods studied, a significant difference existed not only in the ranks of the RI (MannWhitney $U$ rank sum test, $\mathrm{p}<0.0001$ ), but also in positivity (Fisher's exact test, $\mathrm{p}<0.0001$ ). Due to the small number of samples, no difference was observed in the third collection (Mann-Whitney $U$ rank sum test, $\mathrm{p}=$ 0.9549; Fisher's exact test, $\mathrm{p}=0.6029$ ).

TABLE I

Samples from pregnant women positive by real-time and nested polymerase chain reaction (PCR)

\begin{tabular}{|c|c|c|c|c|c|c|c|c|}
\hline \multirow[b]{2}{*}{ Sample } & \multicolumn{2}{|c|}{ First collection } & \multicolumn{2}{|c|}{ Second collection } & \multicolumn{2}{|c|}{ Third collection } & \multicolumn{2}{|c|}{ Postpartum } \\
\hline & $\begin{array}{l}\text { Real-time } \\
\text { (Ct) }\end{array}$ & Nested sp. & $\begin{array}{l}\text { Real-time } \\
\quad(\mathrm{Ct})\end{array}$ & Nested sp. & $\begin{array}{l}\text { Real-time } \\
\text { (Ct) }\end{array}$ & Nested sp. & $\begin{array}{l}\text { Real-time } \\
(\mathrm{Ct})\end{array}$ & Nested sp. \\
\hline B 12 & 36.16 & $P v$ & NEG & NEG & ND & ND & NEG & NEG \\
\hline В 24 & 34.19 & $P m$ & 36.01 & NEG & 37.02 & $P m$ & 35.98 & $P m$ \\
\hline В 59 & 36.91 & $\mathrm{Pm}$ & 36.34 & $P m$ & 35.19 & $P m$ & ND & ND \\
\hline В 65 & 33.22 & $\mathrm{Pm}$ & ND & ND & ND & ND & 32.39 & $P m$ \\
\hline B 72 & 35.23 & $P m$ & NEG & NEG & ND & ND & ND & ND \\
\hline C 3 & NEG & NEG & 34.14 & $P v$ & 32.45 & $P v$ & NEG & NEG \\
\hline B 8 & NEG & NEG & ND & ND & ND & ND & 37.06 & $P v$ \\
\hline
\end{tabular}

the threshold cycles $(\mathrm{Ct})$ represent the average of the duplicates in genus specific real-time PCR assays. Plasmodium vivax (Pv) amplified a fragment of 120 base pairs (bp) and Plasmodium malariae (Pm) 144 bp. ND: not done; NEG: negative. 
TABLE II

Positivity of plasma samples from pregnant women during the quarterly follow-up

\begin{tabular}{lccc}
\hline & \multicolumn{3}{c}{ Sample collections } \\
& \multicolumn{3}{c}{$\mathrm{n} / \mathrm{n}(\%)$} \\
\cline { 2 - 4 } Immunoassay & First & Second & Third \\
\cline { 2 - 4 } ELISA- $P v$ & $50 / 125(40)$ & $27 / 78(34.6)$ & $7 / 17(41.2)$ \\
ELISA- $P f$ & $5 / 125(4)$ & $5 / 75(6.7)$ & $2 / 17(11.7)$ \\
SD Bioline $P v$ & $47 / 125(37.6)$ & $22 / 78(28.2)$ & $7 / 17(41.2)$ \\
SD Bioline $P f$ & $2 / 125(1.6)$ & $0 / 78(0)$ & $1 / 17(5.9)$ \\
IFA- $P m$ & $19 / 125(15.2)$ & $12 / 81(14.8)$ & $2 / 17(11.7)$ \\
\hline
\end{tabular}

ELISA-Plasmodium falciparum $(P f)$ with crude extract of $P$. falciparum from culture; ELISA-Plasmodium vivax $(P v)$ was assayed with $\mathrm{His}_{6} P v \mathrm{MSP}_{19}$ antigen; indirect immunofluorescence assay-Plasmodium malariae (IFA-Pm) with $P$. malariae clinical sample.
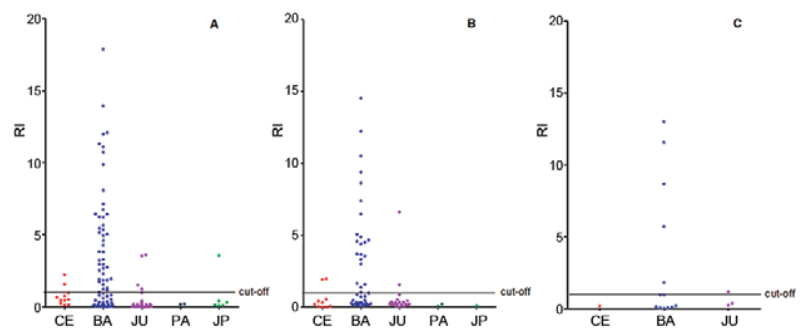

Fig. 2: reactivity index (RI) of plasma samples assayed by ELISA- $P v$ with $\mathrm{His}_{6} P v \mathrm{MSP}_{19}$ recombinant antigen during the follow-up of pregnant women from each locality of the municipality of Juquitiba, state of São Paulo, Brazil. Cut-off $=0.090$. A: first collection $(\mathrm{n}=125)$; B: second collection $(n=78)$; C: third collection $(n=17)$; CE: Centro; BA: Barnabés; JU: Justino; PA: Palmeiras; JP: Jd. das Palmeiras.

Clinical aspects - Among the positive pregnant women, one reported fever and one reported chills. Other non-specific symptoms were reported, such as headache and tiredness. The haemoglobin measures were normal ( $\geq 12 \mathrm{~g} / \mathrm{dL}$ ) in all but one pregnant woman, who presented with a level of $11.4 \mathrm{~g} / \mathrm{dL}$ in the first survey, when she was negative for Plasmodium and $9.8 \mathrm{~g} / \mathrm{dL}$ after she had become infected with $P$. vivax.

\section{DISCUSSION}

For the first time, infections due to $P$. vivax and $P$. $m a$ lariae were detected in pregnant women living in a lowendemicity area of the Brazilian southeastern coast. No displacements outside SP were reported by these women. In the extra-Amazon Region, 691 malaria cases diagnosed by TBS were reported in 2013, most having been imported from the Amazon Region or other countries and presenting with classical malaria symptoms. Among them, 84 were autochthonous and ES, SP and PI reported $79.8 \%$ (MS 2014b). Most cases are oligosymptomatic and present low parasitaemias, thereby decreasing the op- portunity of detection by haemoscopy. The diagnosis of Plasmodium by TBS enables species differentiation and quantification. However, the sensitivity depends on the microscopist's experience and can range from 5-500 parasites/ $\mu \mathrm{L}$ (Milne et al. 1994). In this context, molecular tools based on the detection of parasite DNA are very useful (Snounou et al. 1993, Lima et al. 2011).

In SP, autochthonous transmission was detected along the northeastern and southeastern coasts, which was associated with the close contact between humans and the Atlantic Forest biome, leading to exposure to Anopheles mosquitoes, whose breeding grounds are the bromeliads (Deane 1992, Curado et al. 2006, Marques et al. 2008). Cerutti et al. (2007) offered two hypotheses for such transmission in a similar setting. The first is a suspected greater number of undetected cases, which are self-limited or asymptomatic. The second is the presence of simian reservoirs of parasites, acting as a source of infection for humans. This latter hypothesis is corroborated by the fact that autochthonous $P$. malariae was detected in SP by our group. It is important to note that $P$. malariae from humans is undistinguishable from $P$. brasilianum, which infects non-human primates, suggesting a host transfer (Escalante et al. 1998), as well as $P$. vivax and $P$. simium (Escalante et al. 2005). In a survey of non-human primates in Brazil, the highest infection rate $(35.6 \%)$ was recorded in the southeastern region, with $P$. brasilianum accounting for $46.3 \%$ and $P$. simium for $37.5 \%$ of the positive blood samples (Deane 1992).

The studied area is considered "low-endemicity". However, the asymptomatic cases detected in the region over time suggest a higher transmission rate than has previously been reported. In this scenario, our results showed a positivity of $1.6 \%$ by haemoscopy. The parasitaemias of the two positive TBSs were 24 parasites $/ \mu \mathrm{L}$, in agreement with previous reports of autochthonous cases in SP, when very low parasitaemias represented $61 \%$ of the infections (Couto et al. 2010). Because the inclusion criteria had included all pregnant women in the five public healthcare units of Juquitiba who agreed to participate, sample selection bias should not be expected. The positivity of real-time and nested PCR was 5.6\%. Six out seven (4.8\%) of the positive pregnant women resided in Barnabés, a district located in a rural area, very close to the forest. The other woman, despite living in a central area, probably acquired the infection during displacements to rural areas, because she is a local health worker. It is interesting to note that $P$. vivax was the species reported as the most prevalent in SP, when, based on microscopy data (Carvalho et al. 1988, Marques et al. 2008, Couto et al. 2010), P. malariae and $P$. vivax are frequently misdiagnosed (Kawamoto et al. 2002). Molecular tools are able to detect $P$. malariae in areas where this species is significant for the dynamics of local transmission (Kirchgatter et al. 2005). Our survey showed a prevalence of $3.2 \%$ of $P$. malariae infections in Juquitiba, 3.5 times higher than that reported in ES (Cerutti et al. 2007).

Although serology is not used for malaria diagnosis, it is useful for determining the exposure of individuals, thereby providing significant data on the parasite-host interaction. Junqueira et al. (2007) reported asymptomatic 
P. vivax in the postpartum period of a woman living in the Atlantic Forest area, with IgM and IgG antibodies. Her twin newborns only presented $\operatorname{IgG}$ antibody titres. TBS and PCR resulted in negatives for the mother and the neonates; nevertheless, immunohistochemistry with Plasmodium antigens was positive. The spontaneous clearance of parasitaemia after delivery could explain the negative TBS and PCR results (Nguyen-Dinh et al. 1988). In our study, the same event occurred in a pregnant woman positive for $P$. vivax during the follow-up, for which antibodies presented only in the postpartum period. The ELISA- $P v$ positivity was $44 \%$, in very good agreement with the SD Bioline- $P v(38.4 \%)$, but indicating a high exposure of pregnant women to the parasite. It is important to note that the recombinant antigens used in this study provide a specific antibody response against the MSP1 protein present in the blood stage of Plasmodium, indicating infection instead of merely inoculation of sporozoites, as detected by ELISA protocols based on CSP antigens. On the other hand, IFA is based on crude antigens for the detection of antibodies, thus being less sensitive and specific. This fact may explain IFA's low positivity in an area where $P$. malariae is the most prevalent species.

Studies conducted in a similar scenario reported positivities ranging from $32-49 \%$ (Curado et al. 2006) and $37.7 \%$ (Cerutti et al. 2007) for IFA- $P v$. With respect to the immune response to $P$. malariae in our survey, IFA- $P m$ was positive in $18.4 \%$ of the samples, very similar to the frequency of $16-19.3 \%$ reported by Curado et al. (2006). It is noteworthy that, in ES, PCR showed a positivity of $0.9 \%$ for $P$. malariae, whereas the IFA- $P m$ for IgG antibodies was positive in $7.9 \%$ of residents, suggesting that individuals could present spontaneous cures without specific treatment, because they had no symptoms. In our results, we found higher positivity in both PCR (3.2\%) and IFA-Pm (18.4\%) for the pregnant women. One can argue about the reason for such differences. In fact, our survey was conducted in an immunosuppressed cohort, because pregnant women develop an immune adaptation in order to avoid foetal rejection (Hunt 1992). The maternal immunosuppression is both specific, to maintain the foetus, and nonspecific, increasing the risk of acquiring malaria (Weinberg 1984). Mayor et al. (2013) compared the IgG humoural responses in uninfected pregnant women with those with acute, chronic or past placental infection. The group of infected women showed higher levels of IgG against all parasite and recombinant antigens tested, including $P f \mathrm{MSP}_{19}$. On the other hand, during pregnancy, there is a depression of cell-mediated immunity (Riley et al. 1989) associated with the increased production of hormones essential to maintain gestation. Increased cortisol levels were detected in pregnant women who later developed parasitaemia, thereby suggesting a causal association (Vleugels et al. 1987).

$P$. vivax and $P$. malariae-asymptomatic infections have been described in the studied area (Couto et al. 2010). Due to the lack of symptoms, transfusional malaria cases were reported, when donors transmitted $P$. malariae to recipients, even a long period after the displacement to the Atlantic Forest areas had occurred (Kirchgatter et al. 2005, Scuracchio et al. 2011). The low parasitaemia and the non-specific symptoms observed in the positive pregnant women could be related to the high frequency of IgG antibodies, indicating constant exposure to parasites. The subclinical aspects observed could be explained by the zoonotic profile of the infections, with the transfer of non-adapted parasites between primates and human hosts. The behaviour of An. (K.) cruzii mosquitoes contributes to the maintenance of transmission because their vertical dispersion allows them to feed at the ground and in the canopy (Deane 1992).

The first description of pregnant women harbouring $P$. vivax or $P$. malariae in an area of low transmission in southeastern Brazil has had an impact on the surveillance of malaria transmission in that scenario. It is important to highlight that the subjects tested positive and mentioned no displacement, confirming the autochthony. Data reported here note the need for follow-ups with this special group to detect infection. Considering the low parasitaemias and the asymptomatic profile, the diagnosis should apply very sensitive tools, such as realtime and/or nested PCR, because TBS could not detect parasites in the peripheral blood in these cases. Among the molecular protocols, real-time PCR should be considered the first option for detecting Plasmodium. This assay is based on genus-specific primers, is very sensitive and performs rapidly. Positive samples should be assayed by nested PCR to determine Plasmodium species. Evaluation of exposure to Plasmodium ELISA should be considered due to its high sensitivity. The results obtained herein should encourage other surveys in similar areas, where transmission could be happening without knowledge of the control programs. Other aspects concerning the relationship between pregnant women and $P$. vivax and $P$. malariae should be further investigated, as well as the cell-mediated immune response and immunohistochemical approaches.

In conclusion, despite the benign appearance of malaria in the studied area, the detection of Plasmodium in pregnant women demonstrates the utility of testing for this parasite in routine prenatal care.

\section{ACKNOWLEDGEMENTS}

To all pregnant women of this study, to the staff of the healthcare units (Department of Health of Juquitiba) and to the staff of the Centre for Malaria Research/SUCEN/IMTSP, in special to Maria Silvia AP de Paula, Otacília R Cravo and Christina RC Toniolo.

\section{REFERENCES}

Almeida LB, Barbosa MGV, Martinez-Espinosa FE 2010. Malaria among women aged 10 to 49 years, according to SIVEP-Malaria, Manaus, state of Amazonas, 2003-2006. Rev Soc Bras Med Trop 43: 304-308.

Branquinho MS, Marrelli MT, Curado I, Natal D, Barata JM, Tubaki R, Carréri-Bruno GC, de Menezes RT, Kloetzel JK 1997. Infection of Anopheles (Kerteszia) cruzii by Plasmodium vivax and Plasmodium vivax variant VK247 in the municipalities of São Vicente and Juquitiba, São Paulo. Rev Panam Salud Publica 3: 189-193.

Carvalho ME, Glasser CM, Ciaravolo RMC, Etzel A, Santos LA, Ferreira CS 1988. Sorologia de malaria vivax no foco Aldeia dos Índios, município de Peruíbe, estado de São Paulo, Brasil, 1984 a 1986. Cad Saude Publica 3: 276-292.

Cerutti CJR, Boulos M, Coutinho AF, Hatab MC, Falqueto A, Rezende HR, Duarte AM, Collins W, Malafronte RS 2007. Epidemiologic 
aspects of the malaria transmission cycle in an area of very low incidence in Brazil. Malar J 6: 33.

Coelho JS, Soares IR, Lemos EA, Jimenez MCS, Kudó ME, Moraes SL, Ferreira AW, Sanchez MCA 2007. A multianalyte Dot-ELISA for simultaneous detection of malaria, Chagas disease and syphilisspecific IgG antibodies. Diagn Microbiol Infect Dis 58: 223-230.

Couto RD, Latorre MRDO, Di Santi SM, Natal D 2010. Malária autóctone notificada no estado de São Paulo: aspectos clínicos e epidemiológicos - 1980 a 2007. Rev Soc Bras Med Trop 43: 52-58.

Curado I, Malafronte RS, Duarte AMC, Kirchgatter K, Branquinho MS, Galati EAB 2006. Malaria epidemiology in low-endemicity areas of the Atlantic Forest in the Vale do Ribeira, São Paulo, Brazil. Acta Trop 100: 54-62.

Deane LM 1992. Simian malaria in Brazil. Mem Inst Oswaldo Cruz 87 (Suppl. III): 1-20.

Dellicour S, Tatem AJ, Guerra CA, Snow RW, ter Kuile FO 2010. Quantifying the number of pregnancies at risk of malaria in 2007: a demographic study. PLoS Med 7: 1.

Escalante AA, Cornejo OE, Freeland DE, Poe AC, Durrego E, Collins WE, Lal AA 2005. A monkey's tale: the origin of Plasmodium vivax as a human malaria parasite. Proc Natl Acad Sci USA 102: 1980-1985.

Escalante AA, Freeland DE, Collins WE, Lal AA 1998. The evolution of primate malaria parasites based on the gene encoding cytochrome $\mathrm{b}$ from the linear mitochondrial genome. Proc Natl Acad Sci USA 95: 8124-8129.

Ferreira AW, Sanchez MCA 1988. Malária humana: padronização e otimização de testes sorológicos para diagnóstico individual e inquéritos epidemiológicos. Rev Inst Med Trop Sao Paulo 30: 137-146.

Greiner M, Pfeiffer D, Smith RD 2000. Principles and practical application of the receiver-operating characteristic analysis for diagnostic tests. Prev Vet Med 45: 23-41.

Hunt JS 1992. Immunobiology of pregnancy. Curr Opin Immunol 4: 591-596.

Junqueira FM, Tangerino JC, Silva MV, Rocha MCP, Nogueira SLR, Nascimento LGG, Carvalho M, Kirchgatter K, Araújo RAS, Lima GFMC, Nascimento MJC, Di Santi SM, Duarte MIS 2007. Malária em gestante do município de Tapiraí SP - Relato de caso. Rev Soc Bras Med Trop 40: 143.

Kawamoto F, Win TT, Mizuno S, Lin K, Tantulart IS, Mason DP, Kimura M, Wongsrichanalai C 2002. Unusual Plasmodium malariae-like parasites in Southeast Asia. J Parasitol 88: 350-357.

Kirchgatter K, Nogueira SL, Padilha A, Curado I, Boulos M, Di Santi SM 2005. Lethal malaria caused by Plasmodium malariae in a splenic patient in Brazil. BMJ 331: 576.

Laporta GZ, Ramos DG, Ribeiro MC, Sallum MAM 2011. Habitat suitability of Anopheles vector species and association with human malaria in the Atlantic Forest in south-eastern Brazil. Mem Inst Oswaldo Cruz 106 (Suppl. I): 239-245.

Lima GFMC, Levi JE, Geraldi MP, Sanchez MCA, Segurado AAC, Hristov AD, Inoue J, Costa-Nascimento MJ, Di Santi SM 2011. Malaria diagnosis from pooled blood samples: comparative analysis of real-time PCR, nested PCR and immunoassay as a platform for the molecular and serological diagnosis of malaria on a large-scale. Mem Inst Oswaldo Cruz 106: 691-700.

Luz TCB, Suárez-Mutis MC, Miranda ES, Moritz AFE, Freitas LF, Brasil JC, Osório-de-Castro CGS 2013. Uncomplicated malaria among pregnant women in the Brazilian Amazon: local barriers to prompt and effective case management. Acta Trop 125: 137-142.

Marques GRAM, Condino MLF, Serpa LLN, Cursino TVM 2008. Aspectos epidemiológicos de malária autóctone na Mata Atlân- tica, litoral norte, estado de São Paulo, 1985-2006. Rev Soc Bras Med Trop 41: 386-389.

Martínez-Espinosa FE 2003. Malária e gravidez na Região Amazônica: prevalência de infecção em mulheres de idade fértil de Coari, 20012002, PhD Thesis, Instituto Oswaldo Cruz, Rio de Janeiro, 142 pp.

Mayor A, Kumar U, Bardají A, Gupta P, Jiménez A, Hamad A, Sigaúque B, Singh B, Quintó L, Kumar S, Gupta PK, Chauhan VS, Dobaño C, Alonso PL, Menéndez C, Chitnis CE 2013. Improved pregnancy outcomes in women exposed to malaria with high antibody levels against Plasmodium falciparum. J Infect Dis 207: 1664-1674.

Milne LM, Kyi MS, Chiodini PL, Warhurst DC 1994. Accuracy of routine laboratory diagnosis of malaria in the United Kingdom. $J$ Clin Pathol 47: 740-742.

MS - Ministério da Saúde Brasil 2010. Guia prático de tratamento da malária no Brasil, Série A, Normas e manuais técnicos, MS/Secretaria de Vigilância em Saúde/Coordenação-Geral do Programa Nacional de Controle da Malária, Brasília, 35 pp.

MS - Ministério da Saúde Brasil 2014a. Boletim malária, MS/Secretaria de Vigilância em Saúde/Sistema de Informação de Vigilância Epidemiológica-Malária, Brasília, 12 pp.

MS - Ministério da Saúde Brasil 2014b. Casos confirmados de malaria notificados na região estra-amazônica por espécie parasitária - 2007 a 2012. Available from: public.tableausoftware.com/ profile/jurossi\#!/vizhome/RotinaExtra/1_Serie_ano.

Nguyen-Dinh P, Steketee RW, Greenberg AE, Wirima JJ, Mulenda O, Williams SB 1988. Rapid spontaneous postpartum clearance of Plasmodium falciparum parasitaemia in African women. Lancet 2: $751-752$.

Nosten F, Mcgready R, Simpson JA, Thwai KL, Balkan S, Cho T, Hkirijaroen L, Looareesuwan S, White NJ 1999. Effects of Plasmodium vivax malaria in pregnancy. Lancet 354: 546-549.

Plowe CV, Djimde A, Bouare M, Doumbo O, Wellems TE 1995. Pyrimethamine and proguanil resistance-conferring mutations in Plasmodium falciparum dihydrofolate reductase: polymerase chain reaction methods for surveillance in Africa. Am J Trop Med Hyg 52: 565-568.

Riley EM, Schneider G, Sambou I, Greenwood BM 1989. Suppression of cell-mediated immune responses to malaria antigens in pregnant Gambian women. Am J Trop Med Hyg 40: 141-144.

Sanchez MCA, Avila SLM, Quartier-Oliveira VP, Ferreira AW 1993. Malaria serology: performance of six Plasmodium falciparum antigen extracts and of three ways of determining serum titers in IgG and IgM-ELISA. Rev Inst Med Trop Sao Paulo 35: 495-502.

Scuracchio P, Vieira SD, Dourado DA, Bueno LM, Colella R, RamosSanchez EM, Lima GC, Inoue J, Sanchez MCA, Di Santi SM 2011. Transfusion transmitted malaria: case report of asymptomatic donor harboring Plasmodium malariae. Rev Inst Med Trop Sao Paulo 53: 55-59.

Snounou G, Viriyakosol S, Jarra W, Thaithong S, Brown KN 1993. Identification of the four human malaria parasite species in field samples by the polymerase chain reaction and detection of a high prevalence of mixed infections. Mol Biochem Parasitol 58: 283-289.

Vleugels MP, Eling WM, Rolland R, de Graaf R 1987. Cortisol and loss of malaria immunity in human pregnancy. Br J Obstet Gynaecol 94: 758-764.

Weinberg ED 1984. Pregnancy-associated depression of cell-mediated immunity. Rev Infect Dis 6: 814-831.

WHO - World Health Organization 2009. Malaria microscopy quality assurance manual. Available from: who.int/malaria/publications/ malaria_microscopy_QA_manual.pdf?ua $=1$.

WHO - World Health Organization 2013. World malaria report 2013. Available from: who.int/malaria/publications/world malaria report_2013/en/. 